\title{
PELATIHAN DAN PENDAMPINGAN PENGGUNAAN KIT IPA DI SD NEGERI 34 CAKRANEGARA
}

\author{
Baiq Niswatul Khair ${ }^{1 *}$, Fitri Puji Astria ${ }^{2}$, K. Sri Kusuma Wardani3 ${ }^{3}$, \\ Nurwahidah$^{4}$, N L P. Nina Sriwarthini ${ }^{5}$, Aisa Nikmah Rahmatih ${ }^{6}$ \\ 1,2,3,4,5,6Program Studi Pendidikan Guru Sekolah Dasar, FKIP, Universitas Mataram \\ *e-mail: baiqniswatul_fkip@unram.ac.id ${ }^{1}$
}

\begin{abstract}
The Ministerial Regulation on Basic and Secondary Education Process Standards ensures that the learning process in primary education should be enjoyable. Fun learning can be obtained through scientificbased learning such as practicum or business. But in reality, learning is conventional, namely lectures and discussions. The utilization of sciences KIT as a learning medium that is owned is never used in classroom learning activities. This is shown from the sciences KIT which is still neatly stored and looks dusty. The reason the sciences KIT was not used was because of the inability of the teacher because they had never received training and the training would damage the sciences KIT used so that the teacher preferred to use conventional learning methods and media. The strategy carried out in this service uses several methods of lectures and presentations, question and answer/discussion, and mentoring. Activities that have been implemented can be said to run smoothly according to the planned schedule. There are no obstacles and problems during the activity and all team members can attend every activity. The whole series of activities starting from the opening stage, delivering training materials, training to closing went smoothly without any meaningful school.
\end{abstract}

Keywords: training, mentoring, sciences KIT

\begin{abstract}
Abstrak
Peraturan Menteri tentang Standar Proses Pendidikan Dasar dan Menengah memastikan bahwa proses pembelajaran di pendidikan dasar harus menyenangkan. Pembelajaran yang menyenangkan dapat diperoleh melalui pembelajaran berbasis ilmiah seperti praktikum atau bisnis. Namun pada kenyataannya pembelajaran bersifat konvensional yaitu ceramah dan diskusi. Pemanfaatan KIT IPA sebagai media pembelajaran yang dimiliki tidak pernah digunakan dalam kegiatan pembelajaran di kelas. Hal ini terlihat dari KIT Ilmiah yang masih tersimpan rapi dan terlihat berdebu. Alasan KIT IPA tidak digunakan karena ketidakmampuan guru karena belum pernah mendapatkan pelatihan dan pelatihan tersebut akan merusak KIT IPA yang digunakan sehingga guru lebih memilih menggunakan metode dan media pembelajaran konvensional. Strategi yang dilakukan dalam pengabdian ini menggunakan beberapa metode ceramah dan presentasi, tanya jawab/diskusi, dan pendampingan. Kegiatan yang telah dilaksanakan dapat dikatakan berjalan lancar sesuai dengan jadwal yang telah direncanakan. Tidak ada kendala dan kendala selama kegiatan berlangsung dan seluruh anggota tim dapat mengikuti setiap kegiatan. Seluruh rangkaian kegiatan mulai dari tahap pembukaan, penyampaian materi pelatihan, pelatihan hingga penutupan berjalan lancar tanpa ada sekolah yang berarti.
\end{abstract}

Kata Kunci:pelatihan, pendampinga, Kit IPA

\section{PENDAHULUAN}

Sekolah Dasar Negeri 34 Cakranegara merupakan salah satu sekolah dasar di kecamatan Cakranegara, kota Mataram yang memiliki akreditasi B dengan fasilitas berupa enam ruang kelas yang diperuntukan bagi enam rombongan belajar, dan satu ruang perpustakaan. Pada tahun pembelajaran 2019/2020 SDN 34 Cakranegara telah menerapkan Kurikulum 13 (K-13) sebagai kurikulum pembelajaran (Kemendikbud, 2020). Kurikulum 2013 menuntut adanya proses pembelajaran yang aktif bagi peserta didik melalui kegiatan yang berbasis saintifik (Kemendikbud, 2014).

Salah satu mata pelajaran yang dipelajari di sekolah dasar adalah Ilmu Pengetahuan Alam (IPA). Pelaksanaan pembelajaran berbasis saintifik pada mata pelajaran IPA dapat terlaksana dengan baik apabila ditunjang dengan model dan media pembelajaran yang sesuai. Salah satu media pembelajaran yang dapat menunjang terlaksananya pembelajaran berbasis saintifik, 
khususnya pada mata pelajaran IPA adalah Kumpulan Instrumen Terpadu (KIT) IPA. Menurut Satria dan Sari (2018) KIT IPA adalah media pembelajaran yang membantu guru dalam menjelaskan konsep-konsep IPA agar lebih mudah dipahami oleh peserta didik. Penggunaan KIT IPA dapat membantu peserta didik belajar secara konkret melalui benda nyata yang dapat dilihat, dipegang, dan dirangkai, sehingga pembelajaran lebih menarik dan menyenangkan. Dampak dari ketertarikan dan menyenangkannya kegiatan pembelajaran membuat peserta didik lebih mudah memahami konsep IPA yang disampaikan oleh guru.

Hasil studi pendahuluan berupa observasi dan wawancara di SDN 34 Cakranegara, diketahui bahwa metode pembelajaran pada mata pelajaran IPA guru didominasi dengan ceramah dan diskusi. Guru masih jarang melakukan kegiatan pembelajaran yang berbasis saintifik dengan metode praktikum ataupun demonstrasi. Selain itu guru juga jarang menggunakan media pembelajaran yang dapat menunjang terlaksananya proses pembelajaran berbasis saintifik. Diketahui bahwa SDN 34 Cakranegara memiliki KIT IPA yang dapat digunakan sebagai media pembelajaran IPA. Namun kenyataannya KIT IPA yang dimiliki jarang digunakan dalam kegiatan pembelajaran di kelas. Hal ini ditunjukkan dari KIT IPA yang masih tersimpan rapi dan tampak berdebu. Selain itu berdasarkan hasil wawancara diketahui bahwa KIT IPA tidak digunakan dikarenakan ketidakmampuan guru dalam menggunakannya, walaupun memiliki buku panduan penggunaan. Ketidakmampuan guru dalam menggunakan KIT IPA dikarenakan tidak pernah memperoleh pelatihan dan kekhawatiran akan rusaknya KIT IPA apabila salah digunakan, sehingga guru lebih memilih menggunakan metode dan media pembelajaran konvensional.

Penggunaan metode dan media pembelajaran yang kurang variatif dan efektif akan berpengaruh terhadap minat dan motivasi belajar peserta didik dalam mempelajari konsep sains. Rendahnya minat dan motivasi belajar peserta didik akan berpangaruh terhadap hasil belajarnya. Hasil studi penelitian tentang pemahaman konsep sains yang dilakukan oleh Wardani dan Darmayanti (2020) di SDN 34 Cakranegara menunjukkan nila rata-rata kemampuan awal peserta didik sebesar 43,8. Nilai rata-rata tersebut menunjukkan bahwa kemampuan pemahaman konsep sains peserta didik masih rendah, sehingga guru perlu memperbaiki proses pembelajaran yang selama ini digunakan agar tujuan pembelajaran dapat tercapai lebih optimal. Perbaikan proses pembelajaran dapat dilakukan apabila kemampuan gurunya ditingkatkan. Salah satu peningkatan kemampuan yang dapat diberikan untuk guru, yakni melatih guru agar dapat menggunakan media pembelajaran berbasis saintifik, khususnya KIT IPA.

Hasil analisis situasi di SD Negeri 34 Cakranegara, diketahui beberapa permasalahan yang meliputi:

1. Tuntutan Kurikulum 13 untuk melaksanakan proses pembelajaran yang aktif bagi peserta didik melalui kegiatan yang berbasis saintifik,

2. Pada mata pelajaran IPA guru hanya menggunakan metode pembelajaran konvensional yakni ceramah dan diskusi biasa,

3. Guru jarang menggunakan media pembelajaran yang dapat menunjang terlaksananya proses pembelajaran berbasis saintifik

4. KIT IPA yang dimiliki tidak pernah digunakan dalam kegiatan pembelajaran di kelas,

5. Ketidakmampuan guru dalam menggunakan KIT IPA, walaupun memiliki buku panduan,

6. Guru IPA tidak pernah memperoleh pelatihan KIT IPA,

7. Kekhawatiran akan rusaknya KIT IPA apabila salah digunakan oleh guru,

8. Kemampuan pemahaman konsep sains peserta didik masih rendah.

Permasalahan-permasalahan yang ada di SD Negeri 34 Cakranegara pada umumnya perlu untuk dicari pemecahannya. Alternatif pemecahan masalah yang dapat dilakukan melalui kegiatan pengabdian masyarakat oleh Lembaga Universitas Mataram. Kegiatan tersebut dapat 
berupa kegiatan pelatihan dan pendampingan bagi guru-guru sekolah dasar dalam menggunakan KIT IPA. Berdasarkan uraian permasalahan dan alternatif pemecahannya maka kegiatan pengabdian masyarakat yang berjudul "Pelatihan dan Pendampingan Penggunaan KIT IPA di SD Negeri 34 Cakranegara" perlu untuk dilakukan.

\section{METODE}

Kegiatan pelatihan dan pendampingan penggunaan KIT IPA di SD Negeri 34 Cakranegara dilaksanakan dengan metode ceramah / presentasi, diskusi dan pendampingan. Berikut rincian pelaksanaan kegiatan pelatihan dan pendampingan penggunaan KIT IPA SD :

a. Metode ceramah dan presentasi digunakan saat menyajikan materi kepada guru SD Negeri 34 Cakranegara tentang: i) Hakikat IPA dan Pengertian KIT IPA oleh Baiq Niswatul Khair, M.Pd. dan Aisa Nikmah Rahmatih, M.Pd., ii) Komponen dan Kegunaan KIT IPA SD dalam kegiatan pembelajaran oleh Fitri Puji Astria, M.Pd. dan Nurwahidah, M.Pd., dan iii) Jenis peraga, pembagian materi serta pelaksanaan praktikum sederhana menggunakan KIT IPA oleh Ketut Sri kusuma Wardani, M.Pd. dan Ni Luh Putu Nina Sriwarthini, M.Pd.

b. Metode tanya jawab, dimaksudkan untuk memberi kesempatan kepada sasaran pengabdian masyarakat ini (guru), tentang materi-materi yang mungkin belum dipahami dalam metode poin 3.1, serta masalah-masalah lain yang berhubungan dengan penggunaan KIT IPA SD.

c. Metode pendampingan, digunakan Tim pengabdian sejak dari persiapan, pelaksanaan dan akhir pelaksanaan pengabdian, berupa evaluasi proses pengabdian.

\section{HASIL DAN PEMBAHASAN}

Kegiatan pengabdian kepada masyarakat ini dilakukan di SD Negeri 34 Cakranegara. Rincian kegiatan pelatihan dan pendampingan penggunaan KIT IPA SD adalah sebagai berikut:

Kegiatan pengabdian ini diikuti oleh 10 Guru, 1 orang Kepala Sekolah, dan 1 Orang Pengawas Pembina. Kegiatan diawali dengan pembukaan yang dilakukan oleh Pengawas yaitu Ibu Hj. Irni, S.Pd. Setelah itu, masing-masing tim pengabdian PGSD UNRAM memperkenalkan diri dan dilanjutkan dengan kegiatan pelatihan dan pendampingan. Tim pengabdian selanjutnya memulai untuk memaparkan materi Pelatihan dan Pendampingan Penggunaan KIT IPA SD yang telah disiapkan. Materi pertama adalah pengenalan alat - alat KIT IPA yang disampaikan oleh Ibu Aisa Nikmah Rahmatih, M.Pd. dan Ibu Fitri Puji Astria, M.Pd. Pada kegiatan ini, sebelum pemateri menyampaikan bahan pelatihan guru dibagi menjadi 5 kelompok di mana masing - masing kelompok diberikan 1 KIT IPA SD. Selanjutnya, pemateri menjelaskan setiap nama alat dan bahan yang ada di KIT IPA SD beserta fungsinya. Pemaparan materi ini dilakukan secara runut dan perlahan agar guru benar - benar mengenali alat dan bahan pada KIT IPA SD dengan baik dan tepat. Adapun feedback yang diharapkan dari kegiatan ini adalah dapat menyebutkan kembali minimal lima nama alat dan bahan yang ada di KIT IPA SD. Hal ini dilakukan agar guru semakin mengenal dan mengetahui fungsi masing - masing alat dan bahan pada KIT IPA tersebut dalam kegiatan pembelajaran. Salah satu Guru, yakni Bapak I Gusti Bagus Swendra, S.Pd. mampu menyebutkan nama dan fungsi alat dan bahan dalam KIT IPA SD dengan baik dan tepat. 


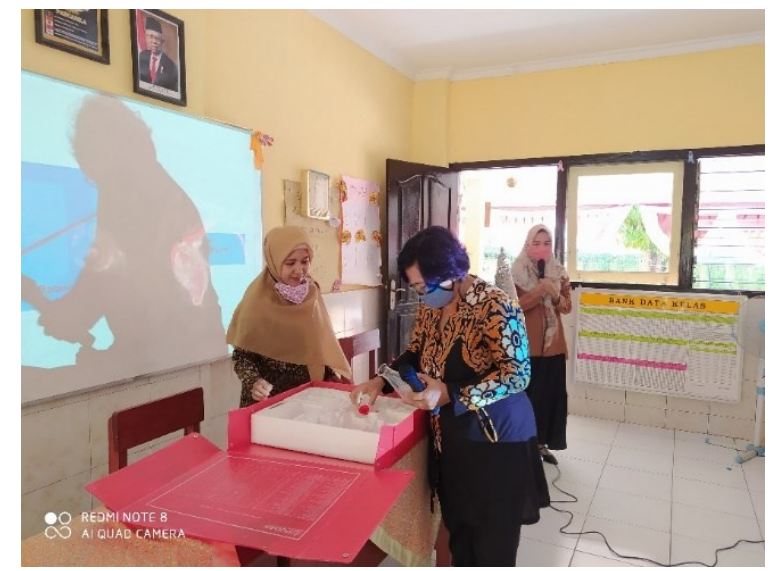

Gambar 1. Guru menyebutkan nama alat dan bahan dalam KIT IPA SD

Materi kedua adalah pendampingan pelaksanaan praktikum menggunakan KIT IPA SD yang disampaikan oleh Ibu Ni Luh Putu Nina Sriwarthini, M.Pd. dan Ibu Nurwahidah, M.Pd. Kegiatan ini diawali dengan menyampaikan judul serta tujuan praktikum. Selanjutnya, pemateri menyebutkan dan menunjukkan alat dan bahan yang digunakan dalam percobaan sederhana yang akan didemonstrasikan. Setelah alat dan bahan yang akan digunakan telah dikeluarkan dari kotak KIT IPA SD, kegiatan berikutnya adalah pendemontrasian percobaan Katrol Sederhana. Guru kemudian memperhatikan dengan seksama setiap tahapan percobaan yang didemonstrasikan oleh pemateri. Guru kemudian melakukan percobaan tersebut bersama kelompok dengan didampingi oleh pemateri.

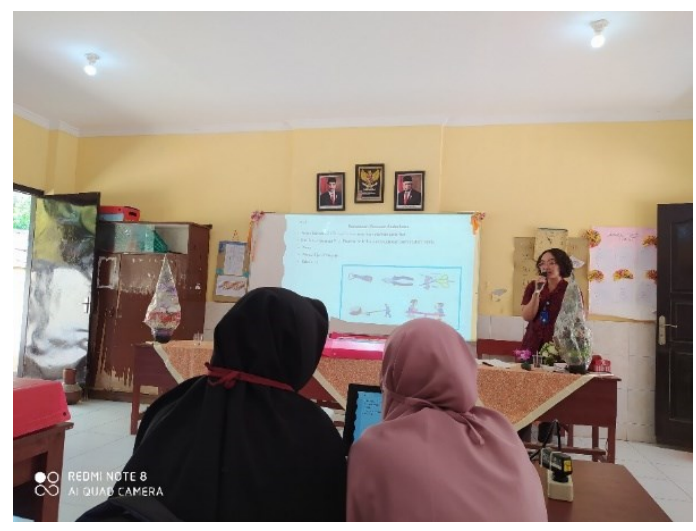

Gambar 2. Penyampaian materi oleh tim

Guru melakukan percobaan sederhana secara seksama berdasarkan demonstrasi pemateri dan buku panduan praktikum yang ada. Setiap tahapan kegiatan percobaan dilakukan oleh guru selayaknya siswa yang melakukan kegiatan praktikum / percobaan di laboratorium. Hasil percobaan kemudian dipaparkan oleh masing - masing kelompok Guru. Pada kegiatan ini, guru terlihat sangat antusias dan semangat dalam melakukan praktikum sederhana tersebut. Guru pun juga membuat kesimpulan dari percobaan dengan mengaitkan konsep awal dengan konsep baru yang terbentuk. 


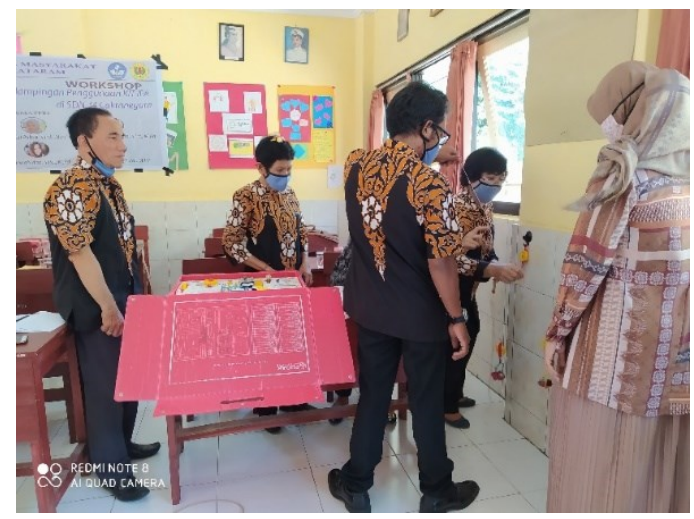

Gambar 3. Guru melakukan praktikum sederhana bersama kelompok

Pada akhir kegiatan, dilakukan diskusi dan tanya jawab terkait seluruh kegiatan pelatihan dan pendampingan penggunaan KIT IPA SD. Pada sesi tanya jawab, seorang guru bertanya mengenai konsep perbedaan berat dan massa. Pertanyaan tersebut kemudian dijawab dan dijelaskan oleh Ibu Baiq Niswatul Khair, M.Pd. Pada penjelasannya, Ibu Baiq Niswatul Khair memaparkan bahwa, massa memiliki satuan yang berbeda dengan berat. Massa memiliki satuan Kilogram sedangkan berat memiliki satuan Newton. Berat dipengaruhi oleh gaya gravitasi sehingga berat suatu benda dapat berubah - ubah sesuai dengan gaya gravitasi yang berlaku pada daerah tertentu misalnya di bumi dan bulan. sedangkan massa suatu benda bersifat tetap. Setelah kegiatan diskusi selesai, kemudian guru peserta pelatihan dan pendampingan beserta Tim pengabdian PGSD melakukan foto bersama. Kegiatan foto bersama adalah kegiatan akhir dari pelatihan dan pendampingan penggunaan KIT IPA SD di SD Negeri 34 Cakranegara. Seluruh kegiatan pelatihan dan pendampingan penggunaan KIT IPA SD di SD Negeri 34 Cakranegara telah terlaksana dengan lancar dan baik.

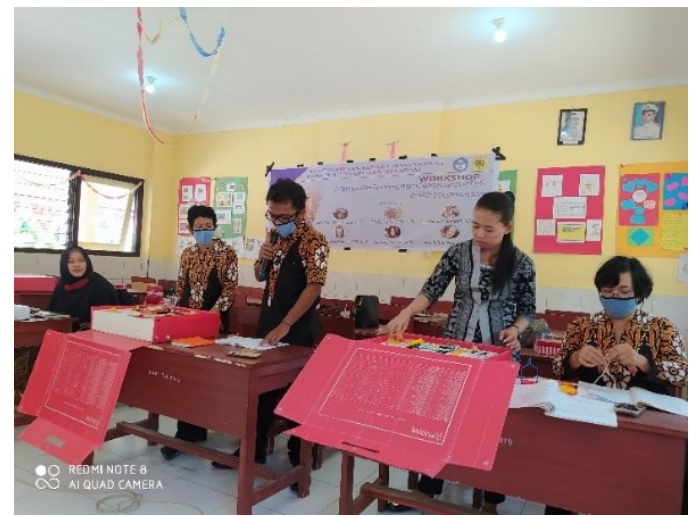

Gambar 4. Guru menyampaikan pertanyaan kepada pemateri

\section{KESIMPULAN}

Berdasarkan hasil kegiatan pengabdian masyarakat dengan tema "Pelatihan dan Pendampingan Penggunaan KIT IPA di SDN 34 Cakranegara" yang telah dilaksanakan maka dapat disimpulan pelaksanaan kegiatan pelatihan dan pendampingan ini berjalan lancar sesuai jadwal yang telah direncanakan. Tidak terdapat hambatan dan masalah selama kegiatan serta seluruh anggota tim dapat hadir melaksanakan setiap tahapan kegiatan. Seluruh rangkaian kegiatan mulai dari tahap pembukaan, penyampaian materi pelatihan, pelatihan hingga penutupan berjalan lancar tanpa adanya suatu kendala berarti. Kegiatan pelatihan dan pendampingan penggunaan KIT IPA, pendidik diberikan tambahan pengetahuan tentang bagaimana cara menggunakan dan memanfaatkan KIT IPA sebagai media pembelajaran IPA. Melalui rangkaian kegiatan pelatihan dan pelatihan tersebut menunjukkan adanya peningkatan kemampuan dan keterampilan guru 
dalam menggunakan alat dan bahan dalam KIT IPA, peningkatan kemampuan guru untuk mensinnergikan pembelajaran dengan penggunaan KIT IPA, serta meningkatnya motivasi guru dalam menyelesaikan permasalahan dalam pembelajaran secara ilmiah.

Terdapat beberapa hal yang dapat direkomendasikan dan dapat ditindaklanjuti dari hasil kegiatan ini adalah sebagai berikut:

1. Diperlukan kesadaran akan pentingnya penggunaan KIT IPA sebagai media pembelajaran yang inovatif dan interaktif.

2. Diperlukan pendampingan yang intensif dan kerjasama semua pihak seperti kepala sekolah dan guru sendiri agar kemampuan dan keterampilan penggunaan KIT IPA yang telah didapatkan dapat diimplementasikan dalam proses pembelajaran.

3. Diperlukan pembiasaan pada guru untuk terus merancang pembelajaran dengan menggunakan media pembelajaran KIT IPA yang inovatif, tidak hanya sesaat setelah kegiatan pelatihan dan pendampingan.

4. Adanya kerjasama yang berkelanjutan antara SD Negeri 34 Cakranegara dengan Prodi PGSD Universitas Mataram untuk meningkatkan kemampuan dan keterampilan guru dalam penggunaan KIT IPA yang inovatif dan sesuai dengan tuntutan jaman.

\section{UCAPAN TERIMA KASIH}

Tim pengabdian kepada masyarakat mengucapkan terimakasih kepada Rektor Universitas Mataram, LPPM Universitas Mataram atas dukungan pendanaan PNBP dari dana DIPA BLU Universitas Mataram tahun anggaran 2020, dengan nomor kontrak perjanjian 1942/UN18/LPPM/2020, Dekan Fakultas Keguruan dan Ilmu Pendidikan Universitas Mataram, Kepala SDN 34 Cakranegara dan seluruh jajarannya, serta semua pihak yang telah berkontribusi terhadap kegiatan ini.

\section{DAFTAR PUSTAKA}

Arsyad, Azhar. (2004). Media Pembelajaran. Jakarta : PT. Raja Grafindo Persada.

E. Mulyasa, (2002). Manajemen Berbasis Sekolah. Bandung: Remaja Rosdakarya.

Kemendikbud. (2014). Materi Pelatihan Implementasi Kurikulum 2013. Jakarta: Badan PSDM dan PMP Kemendikbud.

Kemendikbud. (2020). Data Pokok Pendidikan Dasar dan Menengah. Diakses pada tanggal 15 Februari 2020 melalui https://dapo.dikdasmen.kemdikbud.go.id/

Muthmainnah, dkk. (2016). Pelatihan Penggunaan KIT IPA Bagi Guru Sains di SD Negeri 28 Peusangan dan MIN Krueng Panjoe Kabupaten Bireuen Propinsi Aceh. Jurnal Prosiding Vol. 3, No. 1. ISSN: 2355-3650.

Satria, E. \& Sari, S.,G. (2018). Penggunaan Alat Peraga dan KIT IPA oleh Guru dalam Pembelajaran di Beberapa Sekolah Dasar di Kecamatan Padang Utara dan Nanggalo Kota Padang. Ikraith-Humaniora, Vol. 2, No.2. (1-8).

Sugiyono. (2016). Metode Penelitian Kuantitatif, Kualitatif dan R\&D. Bandung: PT Alfabeta.

Sukmarani, D., dkk. (2016). Dampak Pelatihan KIT IPA terhadap Pengembangan Kemampuan Saintifik Guru Sekolah Dasar di Magelang. Jurnal Penelitian \& Artikel Pendidikan. Hal 1-5.

Suparno. (2001). Teori Perkembangan KognitifJean Piaget. Yogyakarta: Kanisius.

Suryabrata, Sumadi. (2008). Metodologi Penelitian. Jakarta: Raja Grafindo Persada.

Wardani, K.,S.,K. \& Darmayanti, N., W., S. (2020). Efektivitas Pembelajaran Kooperatif Tipe Jigsaw II Bermuatan Content Local Genius untuk Meningkatkan Pemahaman Konsep Sains Siswa. Jurna Elementary, Vol.3, No.1. (32-36). 